\title{
Prevalence of secondary dapsone-resistant leprosy in Upper Volta
}

\author{
S R PATTYN*, A YADA $\dagger$, H SANSARRICQ \\ \& L VAN LOO \\ * Leprosy Laboratory, Institute for Tropical Medicine, Antwerp, \\ Belgium; † Epidémiologiste, Ministère de la Santé Publique, Haute \\ Volta; $\ddagger$ Leprosy Unit, WHO, Geneva
}

Accepted for publication 13 February 1984

\begin{abstract}
Summary A secondary dapsone-resistance survey was performed in 3 health sectors of Upper Volta in 1981-82, among a total population of 994 lepromatous patients. Prevalence of secondary dapsone resistance was found to be 7, 4 and $1 \%$ respectively. Analysis of the results reveals that considerable loss of viability of Mycobacterium leprae occurred in the specimens during transportation and was much more pronounced in the 2 sectors with the lower dapsone-resistance prevalence figures. It is therefore strongly suspected that the $7 \%$ prevalence is also representative of the sectors where the low prevalence figures were found. For other reasons discussed, the $7 \%$ figure must in its turn be a minimum.
\end{abstract}

\section{Introduction}

Upper Volta is a land-locked country in West Africa, surrounded by Côte d'Ivoire, Ghana, Togo and Benin (South), Niger (East) and Mali (North and West) covering an area of $274,000 \mathrm{~km}^{2}$ with a population of about 7 million. The capital is Ouagadougou with an international airport.

Leprosy control activities have been significantly strengthened since 1953. The whole population has been surveyed and clinically examined at regular intervals. Leprosy patients have been registered and treated.

Dapsone was administered mainly in the form of tablets distributed weekly (600 $\mathrm{mg}$ being taken under supervision) during the dry season (September-June) while during the rainy season patients were given 60 tablets of $100 \mathrm{mg}$ dapsone ( 1 tablet to be taken daily). In some cases, depending on distances and density of patients, dapsone was given by injection (suspension in chaulmoogra oil, $1200 \mathrm{mg}$ in $5 \mathrm{ml}$ ) once a fortnight.

In 1979 the Ministry of Health of Upper Volta asked THELEP whether a study on the prevalence of secondary dapsone resistance could be performed. 


\section{Method}

By the end of 19792 of the authors (SRP and HS) visited Upper Volta, to investigate the possibilities, and identify 1 or more areas with a high leprosy prevalence, good records and transportation facilities. Using these factors as a basis a preliminary assessment was performed in health sector 1, Ouagadougou, sector 5, Koudougou and sector 7, Bobo-Dioulasso, the latter 2 having a daily train connection in the evening and night with Ouagadougou. In each sector 3 specialized paramedical workers were responsible for the rural leprosy control activities, there was laboratory space available, and a new binocular microscope.

A formal agreement for a research project on a survey of secondary dapsone-resistant leprosy in Upper Volta was signed by the national authorities and the Special Programme for Research and Training in Tropical Diseases.

It was decided to write a protocol detailing all activities, and to organize a 3-week training session for the 9 paramedical workers in Ouagadougou, for training in standardized clinical evaluation, smear-taking, staining slides, BI reading and biopsy taking.

The necessary equipment was provided: slides, boxes, stains, bottles, staining racks, individual patient records, registers, local anaesthetic, biopsy sets, biopsy containers, crates, vehicles and petrol.

All biopsies were to be centralized in Ouagadougou and shipped by air to the laboratory in Antwerp. The instructors of the training session were Dr Baquillon and $\mathrm{Mr}$ Ouologuem, both from the Institut Marchoux, Bamako, Mali. $\mathrm{Mr}$ Ouologuem, laboratory technician, had previously participated in a THELEP Standardization Workshop on smear-taking and reading. The session was organized in May 1980, and conducted following a specific protocol prepared by one of us (SRP). It was planned that from October to December 1980 all registered lepromatous patients, diagnosed prior to 1975 would be visited as well as all lepromatous patients who had abandoned treatment and who had presented themselves again with relapse, between 1975 and 1979, and had not been given rifampicin or clofazimine.

During this first visit a new individual patient file had to be made and smears taken from 4 sites: 2 earlobes and either 2 or 1 active skin lesions plus either forefront, thorax, back, lumbar region, arm, thigh, elbow or dorsum of a finger.

At each sector the slides were to be stained, examined and the BI calculated. During a second visit a skin biopsy was to be taken from those patients who had a $\mathrm{BI}>2$ at any site other than the earlobes, and sent on wet ice in a thermos flask to Ouagadougou. Each sector would take a maximum of 3 biopsies per week, in order to limit the total number of biopsies arriving weekly in Antwerp to 9.

Due to the late arrival of some supplies and other factors, the work could only start early in 1981. 62 biopsies were taken between June and September 1981, and 4 between March and June 1982. 
The mouse foot-pad (MFP) technique for dapsone sensitivity testing was as described previously. ${ }^{1}$

\section{Results}

Table 1 shows the overall results. In sector 1, Ouagadougou, 35 lepromatous patients, $9.8 \%$ of the total were biopsied, all biopsies contained a sufficient number of bacilli to be inoculated into mice. In 5 cases there was no multiplication in the mouse foot-pads, 5 strains were dapsone sensitive and 25 were dapsone resistant, 16 of which to the highest concentration tested: $10^{-2} \mathrm{~g} \%$ dapsone in the mouse diet. The overall prevalence of secondary dapsone resistance is $7 \%$.

Table 1. Population, prevalence of leprosy, lepromatous leprosy and dapsone resistance in 3 sectors of Upper Volta

\begin{tabular}{|c|c|c|c|}
\hline & $\begin{array}{c}\text { Sector } 1 \\
\text { Ouagadougou }\end{array}$ & $\begin{array}{c}\text { Sector } 5 \\
\text { Koudougou }\end{array}$ & $\begin{array}{c}\text { Sector } 7 \\
\text { Bobo-Dioulasso }\end{array}$ \\
\hline $\begin{array}{l}\text { Population } \\
\text { Leprosy pat. } \\
\text { Lepromatous }\end{array}$ & $\begin{array}{r}1,022,578 \\
9875\left(9^{\circ}{ }^{\circ \circ}\right) \\
355(3.5 \%)\end{array}$ & $\begin{array}{c}654,688 \\
4833\left(7^{\circ} \%^{\circ \circ}\right) \\
196\left(4^{\circ} \%\right)\end{array}$ & $\begin{array}{l}441,296 \\
1909\left(4^{\circ} \%^{\circ}\right) \\
443(23 \%)\end{array}$ \\
\hline $\begin{array}{l}\text { Biopsied } \\
\text { Not inoc. } \\
\text { No growth } \\
\mathrm{S} \\
\mathrm{R} 10^{-4} \mathrm{~g} \% \\
\quad 10^{-3} \mathrm{~g} \% \\
10^{-2} \mathrm{~g} \%\end{array}$ & $\begin{array}{l}35(9 \cdot 8 \%) \\
- \\
5(14 \%) \\
5 \\
3) \\
6) 7 \% \\
16)\end{array}$ & $\begin{array}{l}22(11 \cdot 2 \%) \\
3 \\
8(42 \%)^{*} \\
3 \\
-) \\
\text { 2) } 4 \% \\
6)\end{array}$ & $\begin{array}{l}9(2 \%) \\
- \\
4(44 \%) \\
- \\
\text { 2) } \\
\text {-) } 1 \cdot 1 \%\end{array}$ \\
\hline
\end{tabular}

* $42 \%$ for 8 out of 19.

In Koudougou 22 biopsies, from $11.2 \%$ of all lepromatous patients, were taken. Three contained no bacilli and were not inoculated, in 8 cases there was no multiplication, 3 strains were dapsone sensitive, 8 were resistant. Based on these results the overall prevalence of dapsone resistance in the Koudougou sector is $4 \%$.

An unexpected low number of biopsies was received from sector 7: from only $2 \%$ of the lepromatous patients. Bacilli from 2 biopsies did not multiply in mice, in 2 cases multiplication was observed in only 1 control mouse out of 5 , these were also interpreted as negative for growth. Five strains were resistant. Based on these results, the prevalence of secondary dapsone resistance in Bobo-Dioulasso sector is $1.1 \%$. 


\section{Discussion}

From 64 patients out of 66 biopsied we received also the corresponding slides of the skin smears for control. Of the 256 smears examined, $44(17 \%)$ gave a difference of more than 1 unit in the readings, in most cases in the sense of higher scores in Upper Volta as compared with Antwerp.

Of the 66 biopsies, 3 were not inoculated because no bacilli were found in the smears from the suspensions. All 3 came from sector 5 . The BI in the corresponding skin smears had been recorded 6 months earlier as 5, 0 and 3 with readings in Antwerp of 3,2 and 3 respectively. Thus in these cases the biopsy site had been wrongly chosen. It may be advantageous to take the biopsies as shortly as possible after the skin smears have been examined.

Where the THELEP standard protocol for dapsone-resistance surveys indicates that biopsies should be taken from skin sites with a $\mathrm{BI} \geqslant 3$, the Upper Volta Protocol stated that biopsies were to be taken from any site other than the earlobes that revealed a $\mathrm{BI} \geqslant 2$. Four such biopsies (Table 2 ) were received. One multiplied regularly in mice. Three gave very weak results in the control mice, 1 of which was dapsone resistant, the 2 others have been interpreted as giving no growth. In so far that BI readings may be somewhat erroneous there may be a small advantage in including biopsies from skin smears with a BI of 2 .

In 9 other cases bacterial multiplication occurred in only part of the control mice (Table 3), in only 1 case was the strain considered as dapsone sensitive, although with only 2 control mice out of 5 showing bacterial multiplication, and the mice fed the lowest concentration of dapsone not examined, this interpretation is debatable.

Multiplication in only a proportion of the mice inoculated may be the result of poor survival of Mycobacterium leprae in the biopsies, most probably as a result of transportation. In this respect it is remarkable that all these cases originated

Table 2. Results of MFP inoculation of biopsies with a BI $=2$ in the corresponding skin smears

\begin{tabular}{|c|c|c|c|c|c|c|c|}
\hline & $\begin{array}{l}\text { BI } \\
\text { UV }\end{array}$ & $\begin{array}{c}\text { BI } \\
\text { AN }\end{array}$ & $\begin{array}{c}\mathrm{AFB} / \mathrm{g} \\
\text { tissue }\end{array}$ & Controls & $10^{-2} \mathrm{~g} \%$ & $10^{-3} \mathrm{~g} \%$ & $10^{-4} \mathrm{~g} \%$ DDS \\
\hline$n^{\circ} 1$ & 2 & 3 & $2 \cdot 710^{7}$ & $5 / 5$ & $0 / 5$ & $5 / 5$ & $5 / 5$ \\
\hline $\mathrm{n}^{\circ} 2$ & 2 & 0 & $9 \cdot 10^{8}$ & $1 / 5$ & $0 / 5$ & $1 / 5$ & $3 / 5$ \\
\hline $\mathrm{n}^{\circ} 3$ & 2 & 2 & $1 \cdot 810^{8}$ & $1 / 5$ & n.e. & $0 / 5$ & $0 / 5$ \\
\hline$n^{\circ} 4$ & 2 & 3 & $1 \cdot 510^{7}$ & $1 / 5$ & n.e. & $0 / 5$ & $0 / 5$ \\
\hline
\end{tabular}

$\mathrm{BI} U \mathrm{~V}=\mathrm{BI}$ reading in Upper Volta.

$\mathrm{BI} A \mathrm{AN}=\mathrm{BI}$ reading in Antwerp.

AFB: acid fast bacilli.

n.e.: not examined. 
Table 3. Results with strains multiplying on only a proportion of the controlled mice

\begin{tabular}{llcccc}
\hline & \multicolumn{4}{c}{ Results in mice fed DDS } & Interpre- \\
Strain $\mathrm{n}^{\circ}$ & 0 & $10^{-2} \mathrm{~g} \%$ & $10^{-3} \mathrm{~g} \%$ & $10^{-4} \mathrm{~g} \%$ & tation \\
\hline 319 & $2\left(^{*}\right)$ & 0 & 0 & n.e. & $\mathrm{S}$ \\
331 & 2 & 2 & 3 & 3 & $\mathrm{R}$ \\
333 & 4 & 5 & 5 & 5 & $\mathrm{R}$ \\
341 & 4 & 0 & 5 & n.e. & $\mathrm{R}$ \\
346 & 4 & n.e. & 0 & 3 & $\mathrm{R}$ \\
347 & 3 & 1 & 2 & 1 & $\mathrm{R}$ \\
361 & 3 & 0 & 1 & 3 & $\mathrm{R}$ \\
423 & 1 & 0 & 0 & 3 & $\mathrm{R}$ \\
424 & 3 & 4 & 4 & n.e. & $\mathrm{R}$ \\
\hline
\end{tabular}

(*) number of mice showing multiplication in foot-pads, always on a total of 5 .

n.e.: not examined.

S: sensitive.

$\mathrm{R}$ : resistant.

from sector 1, Ouagadougou, from which, compared with the other 2 sectors, the lowest proportion of biopsies giving no growth were obtained $(16 \%)$. However, if the number of biopsies giving 'irregular' growth and those producing no growth are added, this category represents $40 \%$ of the biopsies. This figure is of the same magnitude as the 42 and $44 \%$ biopsies from the 2 other sectors, giving no growth in the MFP. During 2 studies previously done in collaboration with the Institut Marchoux, Bamako, Mali ${ }^{1,2}$ where the biopsies were taken to the Institute for shipment to Antwerp, respectively 14 and $25 \%$ of these failed to multiply, a significantly lower figure.

It may thus be concluded that there was a considerable loss of viability of $M$. leprae in the biopsies during this study, but that in the sector of Ouagadougou harm was limited probably due to somewhat better conditions of storage and transportation as compared with the 2 other sectors.

At first sight there seem to be considerable differences in the prevalence figures of secondary dapsone resistance in 3 nearby regions of a highly leprosy endemic country in West Africa (Table 1).

However, these differences may be more apparent than true. There was a significantly greater number of biopsies not giving rise to multiplication from sector 5 compared with sector $1(P=0 \cdot 04)$. This was not the result of longer periods in transit or the biopsies containing a smaller number of bacilli. As discussed above this is probably the result of greater difficulties for refrigeration during transport on some occasions. If a greater fraction of biopsies from sector 5 had survived transportation and subsequently multiplied in mice, even 'irregu- 
larly', it is probable that some of these would have shown dapsone resistance, increasing the prevalence figure to near that for sector 1 .

The situation in sector 7 is also significantly different from that in the other 2 sectors studied. We strongly suspect that the work in sector 7 was not performed as strictly as described in the protocol. Two incidents indicate this. During the survey we were informed about difficulties encountered locally with the staining and reading of the smears. Although efforts were made to gather precise information and to give advice by cable and telex, most probably this was of little help. Furthermore, the protocol prescribed that all positive skin smears and $10 \%$ of the negative ones should be sent to Antwerp, but all the latter arrived broken.

In conclusion, it may be stated that in 1981-82 in 3 regions of Upper Volta, the mean prevalence of dapsone resistance was $3.8 \%$, varying between 7,4 and $1 \%$, but that the lower figures are most probably untrue due to shortcomings in the methodology.

Furthermore, studies of this kind can make no error in producing figures which are too high, since no patients were biopsied twice. The only error possible is that some patients with dapsone resistance have not been seen, examined and biopsied. It is rather astonishing that none of the patients from whom skin smears had been taken, were missed during the second visit for biopsy taking. Therefore, the $7 \%$ prevalence of dapsone resistance must be a minimum.

During the site visit in Upper Volta in 1979, biopsies from 4 patients hospitalized in Ouagadougou and suspected of dapsone resistance were brought to Antwerp and shown to be fully dapsone resistant in the MFP test. ${ }^{3}$ These patients were included in the 1981-82 survey, again biopsied and inoculated into mice. One did not multiply, dapsone resistance was confirmed in the 3 others.

As shown in Table 4, duration of therapy before the detection of dapsone resistance was generally long with mean durations in excess of 20 years. The earliest appearance of secondary dapsone resistance in this study was 8 years: 2

Table 4. Duration of previous therapy

\begin{tabular}{llccc}
\hline & & Sector 1 & Sector 5 & Sector 7 \\
\hline $\mathrm{R} 10^{-2}$ & mean & $22 \cdot 6$ & $25 \cdot 3$ & - \\
& range & $8-35$ & $19-31$ & $13-30-32$ \\
& median & 23 & 23 & - \\
$\mathrm{R} 10^{-3}$ & mean & 25 & $32-33$ & - \\
& range & $9-33$ & - & \\
& median & 27 & - & \\
$\mathrm{R} 10^{-4}$ & mean & $16 \cdot 6$ & - & \\
& range & $8-22$ & & $17-27$ \\
& median & 20 & & \\
\hline
\end{tabular}


patients in sector 1,1 with bacilli resistant against $10^{-2} \mathrm{~g} \%$ dapsone and the second with bacilli resistant against $10^{-4} \mathrm{~g} \%$ dapsone in the diet.

The first study on dapsone-resistant leprosy in West Africa in $1979^{1}$ showed a prevalence of $5.7 \%$ resistance among a population of old lepromatous cases residing near the Institut Marchoux in Bamako, Mali. A second study, performed during 1979-82 among another population in the city, revealed a prevalence of $2 \cdot 3 \%{ }^{2}$ Dapsone resistance has since been found in all countries where it has been sought: ${ }^{4}$ it is at least $5 \%$ everywhere and on the increase. The results of the present study show that the mean prevalence of dapsone resistance in the rural areas of Upper Volta is $3.8 \%$ but in some areas reaches $7 \%$, and such areas may be representative for the whole country rather than exceptions. This high prevalence is not unexpected since the yearly incidence of dapsone resistance has been found in both Ethiopia ${ }^{4}$ and $\mathrm{Mali}^{2}$ to be in the range of $2 \cdot 5-3 \%$.

As stated in the WHO Technical Report 675, Chemotherapy of Leprosy in Control Programmes, the situation concerning dapsone resistant leprosy is alarming. Furthermore, since the present study was undertaken a still more alarming, although foreseeable fact emerged, namely the very high incidence of primary dapsone resistance in both India and West Africa. ${ }^{5}$

\section{Acknowledgments}

The field work would not have been possible without the collaboration of the medical directors in charge and the paramedical Leprosy Workers in Ouagadougou, Koudougou and Bobo-Dioulasso, Dr F Martin-Samos, WHO Programme Coordinator and Dr Le Van Giat, epidemiologist, WHO Ouagadougou.

This investigation received support from the Chemotherapy of Leprosy (THELEP) component of the UNDP/World Bank/WHO Special Programme for Research and Training in Tropical Diseases, and from Les Fondations Follereau, France. Janssen Pharmaceutica, Beerse, Belgium generously provided the dapsone mouse pellets.

A Van Aerde and G Hooft gave excellent technical assistance.

\section{References}

1 Baquillon G, Ferracci C, Pattyn SR. Dapsone resistant leprosy in a population of Bamako (Mali). Lepr Rev, 1980; 51: 315-19.

2 Baquillon G, Ferracci C, Van Loo L, Pattyn SR. Further results on dapsone resistant leprosy in Bamako (Mali). Lepr Rev, 1983; 54: 19-21.

${ }^{3}$ Pattyn SR, Van Loo G, Sansarricq H. Quatre cas de lèpre dapsone résistants en Haute Volta. Méd Afr Noire, 1981; 28: 147-8.

${ }^{4}$ Leprosy surveillance. Primary and secondary dapsone resistance. WHO, Weekly Epidemiol Rec, 1982; 57: 181-3.

5 Dapsone resistant leprosy. The THELEP approach. Int J Lepr, 1981; 49: 421-5. 